Stanistaw Fortuna*, Jan Górski**, Tomasz SiweK**

\title{
THERMOANEMOMETRICAL STUDY OF FLOW STRUCTURE THROUGH A CENTRIFUGAL FAN
}

\begin{abstract}
Recognition of the spatial kinematics of the flow domain and its relation to the fan impeller geometry has a key influence on the machine design and better performance parameters. In this work some experimental results are presented of the measurements of the absolute velocity, its components and turbulence of the air flow through the radial fan rotor operating in various configurations. As the main measuring tool a three-axial hot-wire anemometer (CTA) probe has been used. The anemometer cooperates with a specialized software prepared by the authors for the spatial analysis of the flow field considered. In particular, the distribution of the circumferential velocity components behind the impeller rim has been examined, which affects directly the fan efficiency. As a result of the flow analysis behind the rotor rim a relationship has been established between the degree of turbulence and the machine efficiency. On the basis of the changes in the averaged-in-time velocity field behind the rim, the outflow of air from the blade passage has been evaluated.
\end{abstract}

Keywords: fans, thermo-anemometer, kinematics of flow, turbulence, efficiency

\section{TERMOANEMOMETRYCZNE BADANIA STRUKTUR PRZEPEYWOWYCH W WENTYLATORZE PROMIENIOWYM}

Poznanie przestrzennej kinematyki przepływu i jej związków z geometria maszyny ma kluczowy wplyw na konstruowanie maszyn o lepszych parametrach pracy. $W$ artykule przedstawiono wyniki badań rozkładu prędkości bezwzględnej, jej składowych oraz turbulencji przeplywu powietrza przez wirnik wentylatora promieniowego pracującego w różnych konfiguracjach. Jako glówne narzędzie pomiarowe wykorzystano trójkanatowy termoanemometr, wspótpracujacy z opracowanym autorskim oprogramowaniem shuzacym do przestrzennej analizy pola przepływu. Badano w szczególności: rozkład obwodowej składowej prędkości za wieńcem - decydujący o przyroście krętu oraz składowej promieniowej - wplywającej na wydajność wentylatora. W wyniku analizy przeptywu za wieńcem wirnikowym, ustalono zależność pomiędzy stopniem turbulencji, a sprawnościa maszyny. Na podstawie uśrednionych w czasie zmian pól prędkości za wieńcem zobrazowano wyplyw powietrza z kanalu międzylopatkowego.

Slowa kluczowe: wentylator, termoanemometr, kinematyka przepływu, turbulencja, sprawność

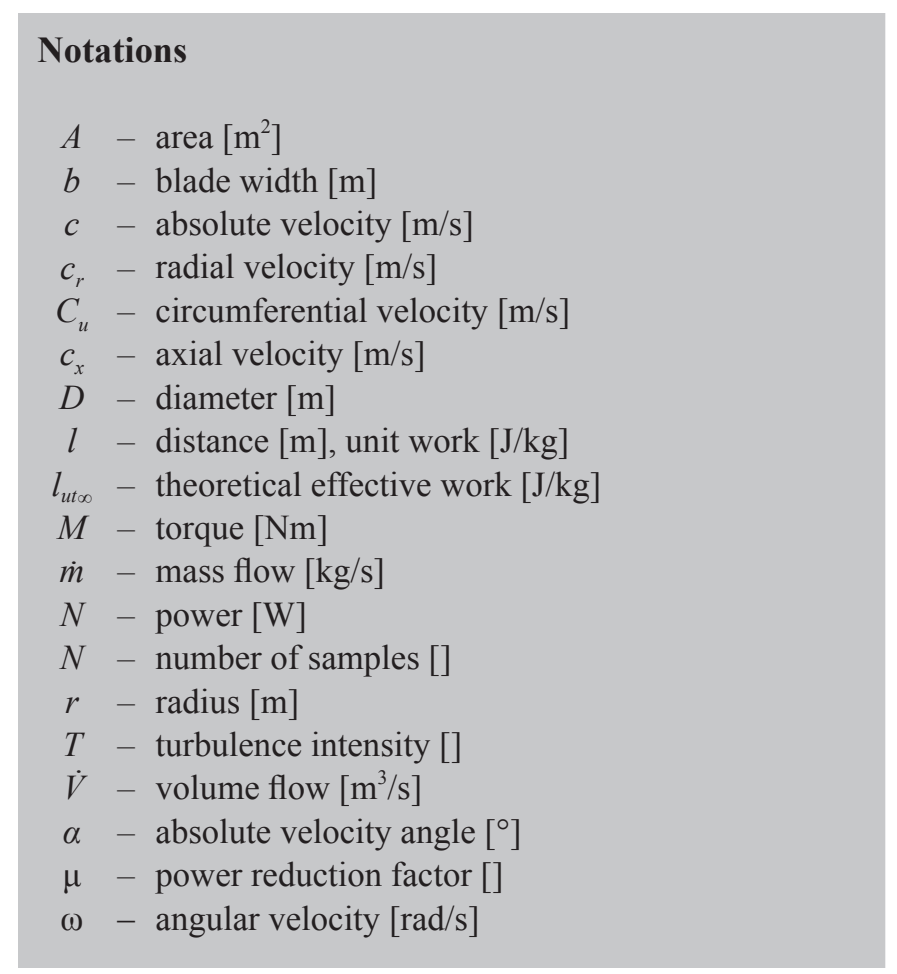

\section{Indices}

1,2 - inlet and outlet from the rotor

- average (superscript)

\section{INTRODUCTION}

One of the most popular topics of discussion in the modern world of politics, media, and also science is pure production and rational energy utilization. Newly arising standards form more and more rigorous restrictions concerning the efficiency of the energy conversion. In fluid-flow machines, the factor which decides about the loss sources, magnitude and the attainable pressure rise is the geometry of the rotor and the housing as well as its influence on the flow structure. Improper flow path generates a number of losses, among other things: changes in the flow direction, separation, flow acceleration or deceleration, mixing, friction, etc. A detailed investigation into the spatial kinematics of the flow through the fan components and its relation to the geometry of the machine permits to develop tools for the units being designed

\footnotetext{
* AGH University of Science and Technology, Faculty of Mechanical Engineering and Robotics, Krakow, Poland

** AGH University of Science and Technology, Faculty of Energy and Fuels, Krakow, Poland, jagorski@agh.edu.pl, siwek@agh.edu.pl
} 
that have better energy parameters, and consequently, have a positive influence on the environment as well as reduced costs of maintenance and exploitation.

This article presents some results of experimental studies on the spatial kinematics of the air flow through a centrifugal fan, operating in two different configurations. On the theoretical ground it is difficult to find an unambiguous description of the complex, three-dimensional internal flow structure. Therefore, in the literature one usually meets simplified models of energy conversion and kinematics in modern centrifugal fans. The real flow is simplified using an elementary configuration, and then, by applying the basic conservation laws and empirical correlations concerning the efficiency and loss coefficients one determines the averaged parameters of the flow field. Analytical methods are not precise enough and often give completely unrealistic results. In the present work, the authors present experimentally developed images of the spatial flow structure at the rotor inlet and outlet of an industrial centrifugal fan.

As the main measuring tool the three-fiber thermo-anemometer probe has been used, enabling the measurement of the absolute velocity of the air flow, its components in the Cartesian coordinate system and their turbulence. Precise positioning of the probe and the developed own software for the processing and analysis of the measurement data enabled the generation of the qualitative images of the complex flow structure. These results are useful for the design of centrifugal fan stages, optimization of the fan geometry, and also for the purposes of the verification of theoretical models used in the computational fluid mechanics (CFD).

The authors pay special attention to the analysis of the relationships between the machine geometry and its performance. Based on the measurement of individual components of absolute velocity, we documented the real influence of the flow structure on the operating parameters of the investigated stage. The circumferential velocity component at the impeller outlet rim corresponds to the increase of the fluid energy in the machine, in compliance with the rule of the preservation of angular momentum. Additionally, the radial component of fluid velocity determines the volume flow rate through the rotor.

During the research tests we obtained detailed results of the analysis of the spatial velocity distribution in the stream incoming to the rotor inlet chamber and in the exit section of the rotor, operating both in the open space and covered by the volute housing, analyzed for two angles of spiral diffuser. For the measuring systems used we carried out the averaging of the individual velocity components along the rotor width. The generated 3-D velocity profiles have been collected on diagrams.

The turbulence intensity and flow unsteadiness were also analysed. The work comprises results for both an isolated rotor and one closed in a volute scroll. In both cases there exists a zone of energy dissipation associated with high turbulence levels. The evaluation of the influence of the flow turbulence intensity on the machine efficiency has been made. The averaged values of turbulence at the rotor outlet for different operating conditions were correlated with the fan efficiency curve. The approximate linear correlation between the internal work and turbulence intensity has been confirmed for a rotor operating in the open space and inside a spiral housing.

\section{MACHINE PERFORMANCE AND THE FLOW KINEMATICS}

An elementary model used in 1-D analysis of the flow in turbo-machines is a well known description given by Euler, which is based on the principle of angular momentum conservation. It states that the sum of the moments of all external forces acting on the fluid, relative to the axis of rotation, is equal to the change of its angular momentum in a given time interval (Dixon 2010). This is described by the formula resulting from Newton's second law of motion:

$$
\sum \bar{M}=\frac{d \bar{K}}{d \tau}
$$

The description used by Euler refers, however, to a very simplified model of the flow, based on the assumptions that the fluid is incompressible and inviscid, the machine rotor consists of an infinite number of zero-thickness blades, the flow through the rotor is axially symmetrical, and there is no pre-rotation of the flow at the rotor inlet. On the basis of equation (1), for a steady uniform flow, one obtains:

$$
\begin{aligned}
M & =\dot{K}_{2}-\dot{K}_{1}=\dot{m} \cdot c_{2} \cdot l_{2}-\dot{m} \cdot c_{1} \cdot l_{1} \\
& =\dot{m} \cdot\left(c_{2} \cdot l_{2}-c_{1} \cdot l_{1}\right)
\end{aligned}
$$

From the trigonometric relations for the radial machine (fig. 1) the following relationships result:

$$
l_{2}=r_{2} \cdot \cos \alpha_{2}, \quad l_{1}=r_{1} \cdot \cos \alpha_{1}
$$

After the substitution of Eq. (3) into Eq. (2) we receive:

$$
M=\dot{m} \cdot\left(c_{2} \cdot r_{2} \cdot \cos \alpha_{2}-c_{1} \cdot r_{1} \cdot \cos \alpha_{1}\right) .
$$

From the triangles of the average speed at the inlet and the outlet of the rotor:

$$
c_{2 u}=c_{2} \cdot \cos \alpha_{2}, \quad c_{1 u}=c_{1} \cdot \cos \alpha_{1},
$$

and after the substitution of Eq. (5) into (4):

$$
M=\dot{m} \cdot\left(c_{2 u} \cdot r_{2}-c_{1 u} \cdot r_{1}\right)
$$

The value of the machine theoretical power is the product of the torque and angular velocity $\omega$ :

$$
\begin{aligned}
N_{u+\infty} & =M \cdot \omega=\dot{m} \cdot\left(c_{2 u} \cdot r_{2} \cdot \omega-c_{1 u} \cdot r_{1} \cdot \omega\right) \\
& =\dot{m} \cdot\left(c_{2 u} \cdot u_{2}-c_{1 u} \cdot u_{1}\right),
\end{aligned}
$$

where:

$$
u_{2}=r_{2} \cdot \omega, \quad u_{1}=r_{1} \cdot \omega
$$




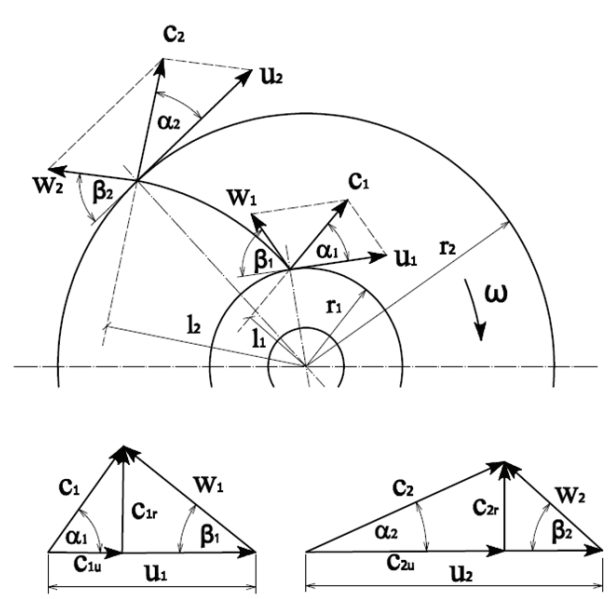

Fig. 1. Kinematics of the radial rotor cascade

The power can also be expressed as the product of the mass flow and specific work:

$$
N_{u t \infty}=\dot{m}=l_{u t \infty}
$$

Therefore, the theoretical work has a direct relation to the kinematics of the flow:

$$
l_{u t \infty}=c_{2 u} \cdot u_{2}-c_{1 u} \cdot u_{1}
$$

This specific work concerns the rotor with the infinite number of blades. In the real machine with a finite number of blades, this relation should be corrected by the introduction of the power reduction factor $\mu$. The formula defining the theoretical work in the real rotor expresses the specific internal work:

$$
l_{u t}=\mu \cdot\left(c_{2 u} \cdot u_{2}-c_{1 u} \cdot u_{1}\right)
$$

In many cases, in the absence of preliminary steering wheels, the term $c_{1 u} \cdot u_{1}$ is often omitted in reflection of the lack of the angular momentum at the inlet. However, experimental research carried out in (Fortuna 2011) proved that the angular momentum frequently exists on the rim of the blade inlet, as it is generated by the presence of inlet chamber walls and the propagation of the flow disturbances opposite to the principal flow direction.

The factor that directly decides about the machine performance is the average absolute velocity radial component in relation to the geometry. For an incompressible fluid the volumetric flow at the rotor outlet can be determined by the equation:

$$
\dot{\mathrm{V}}_{2}=\mathrm{c}_{2 \mathrm{r}} \cdot \mathrm{A}_{2}=\mathrm{c}_{2 \mathrm{r}} \cdot \pi \mathrm{D}_{2} \cdot \mathrm{b}_{2}
$$

In considering the complex, spatial kinematics of the velocity distribution and its components in the machine, and also the propagation of disturbances and non-stationary effects, a deeper analysis concerning the relationships between the flow structures and the particular machine geometry is necessary.

\section{METHODOLOGY OF THE RESEARCH}

An investigation into the spatial structure of the air flow was performed on the radial fan model. Two main cases were considered: 'F2' - when the rotor of the fan works in free space interacting with a suction pipeline, and ' $\mathrm{F} 2+\mathrm{ob}$ ' when the rotor is shut in a housing. In figure 2 are presented the cross-section together with the rotor cascade (fig. 2a) and the isometric view of the investigated fan (fig. 2b).

a)

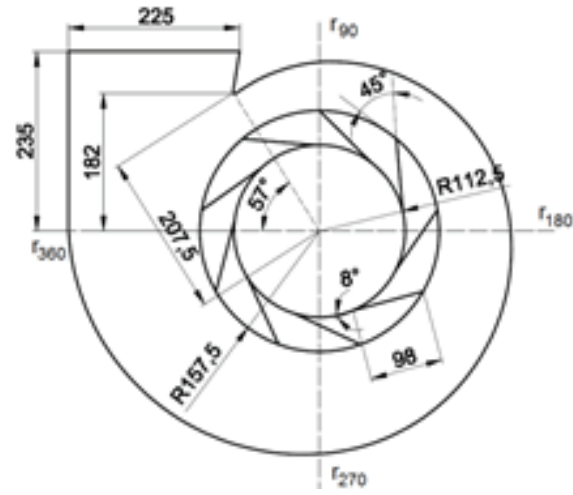

b)

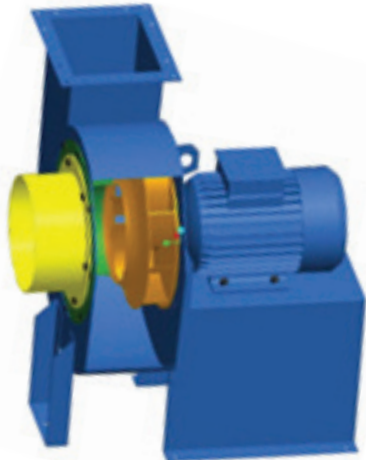

Fig. 2. Fan F2: a) cross-section, b) general view

The measuring setup consisted of a thermo-anemometrical triple wire sensor TURBULENCE METER type ATM 94, operating with a measuring-card A/C PC LabCard PLC 814 installed in a PC computer and the measuring-software prepared by the Laboratory of Flow Metrology (LFM) of the Strata Research Mechanics Institute of the Polish Academy of Sciences (Gawor et al. 1994, Ligęza 2001). The CTA sensors were calibrated in the LFM for their proper velocity response.

The triple wire thermo-anemometer probe (fig. 3) is installed on the arm of a positioning system equipped with two screws, responsible for the displacement of the sensor in the direction parallel to the inlet suction pipe and ensuring the required elevation of the sensor (fig. 4).

For the purpose of the unification of the measurement of velocity components in the characteristic sections of the fan rotor, a system of coordinates related to the position of the thermo-anemometer fiber was assumed (fig. 4a). The axes were selected so that they would be compatible with the directions of the absolute velocity vectors: the axis ' $x$ ' - for axial component $c_{\mathrm{x}}$ (blue), the axis ' $y$ ' - radial component $c_{\mathrm{r}}$ (red), and the axis ' $z$ ' circumferential component $c_{\mathrm{u}}$ (green marked fiber). 


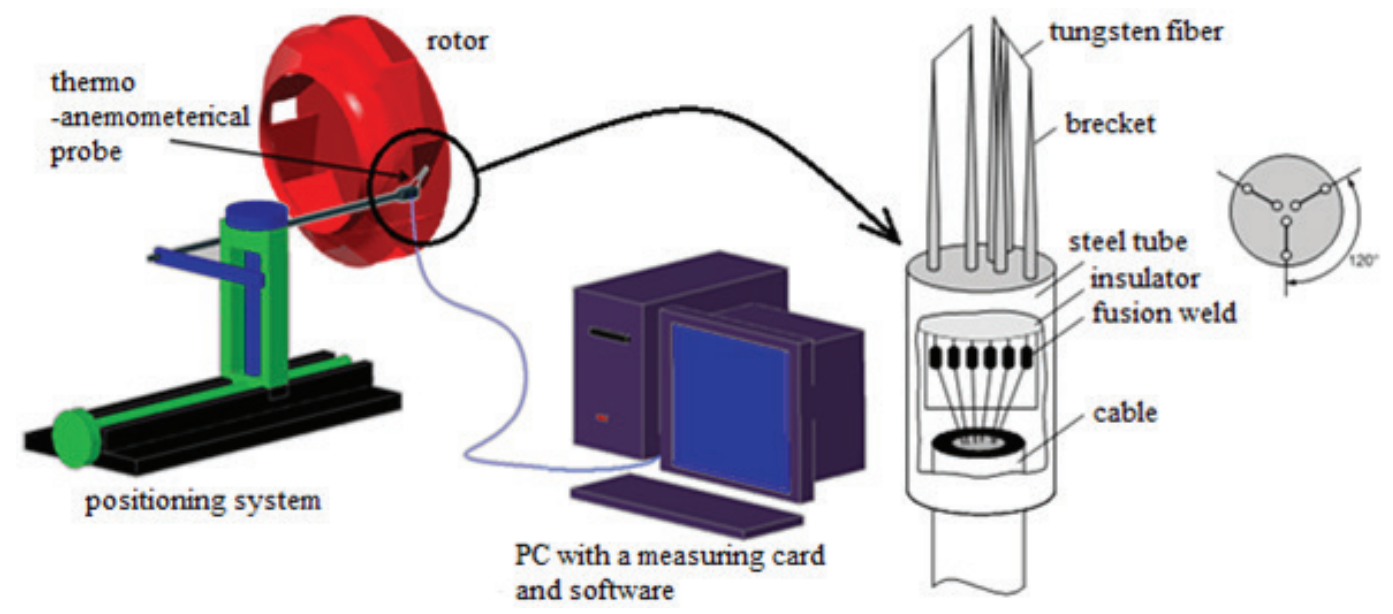

Fig. 3. Positioning of CTA thermo-anemometrical probe

a)

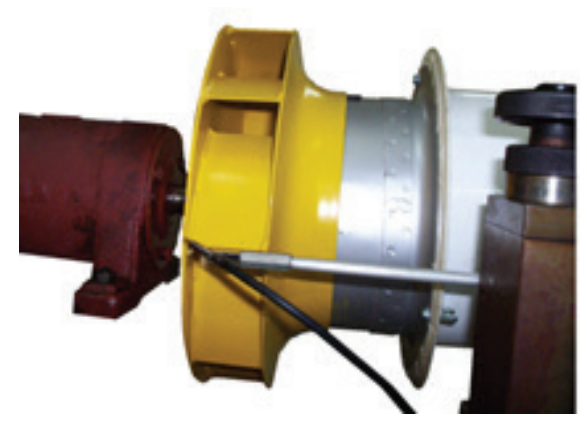

b)

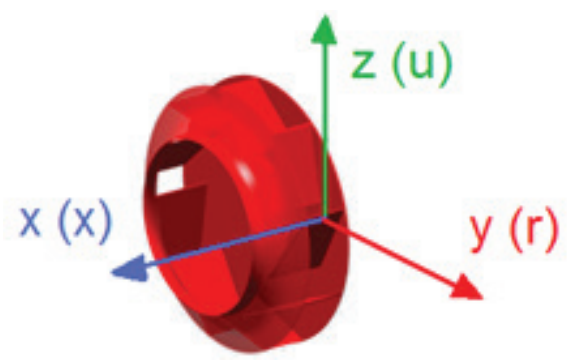

Fig. 4. The adjustment of the thermo-anemometrical probe: a) the coordinate system, b) position of the CTA probe behind the rotor

\section{DISPLAYING THE SPATIAL FLOW STRUCTURE}

The measurement of the flow-field structure was conducted in five planes and for two rotor configurations, i.e., for the rotor operating in the housing $(\mathrm{F} 2+\mathrm{ob})$ and in the free space. A sketch of the basic metrological configurations is presented in the figure 5 .

In each plane there were a dozen or so measuring series performed and additional measuring series were conducted $10 \mathrm{~mm}$ from the preceding ones. The results of an example measuring series, including absolute velocity and individual components has been collected in figure 6 . Each test series is supplemented with the measuring of the results of the turbulence for absolute velocity and its components. The final

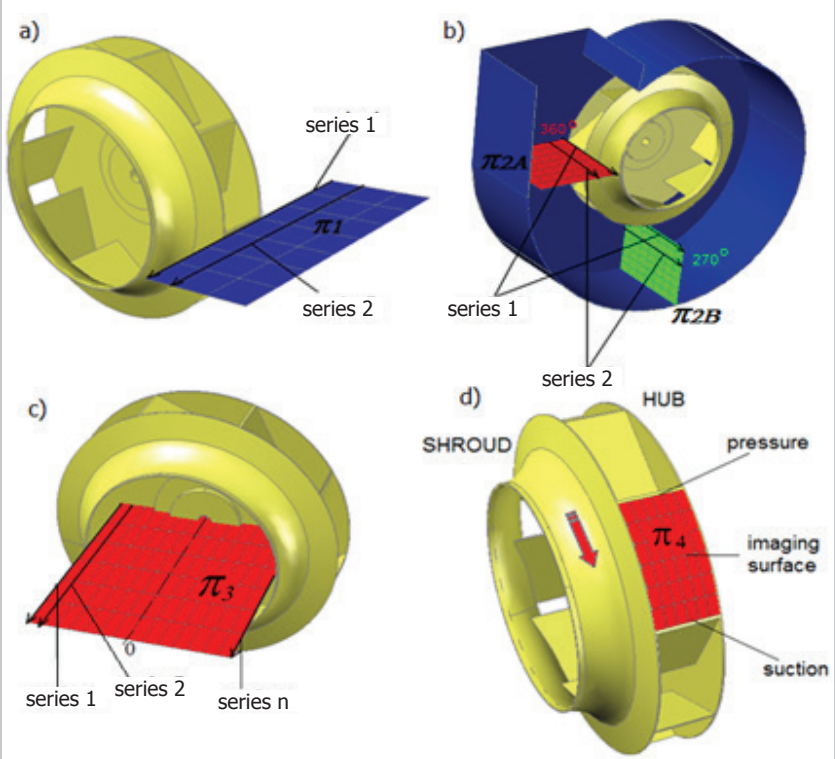

Fig. 5. Measuring planes, a) behind the rotor in free space: b) behind the rotor in the housing, c) in the inlet chamber of the rotor, d) at the blade channel

results of numerical calculations on the measurement data are presented in graphical form of 3D diagrams representing the velocity fields and the 'isotach' maps (lines of constant velocity), see figures $7 \mathrm{c}-\mathrm{d}$. Due to space limitations, only some selected results of the research done are presented.

\subsection{Velocity distribution \\ behind the rotor operating in free space}

The velocity distribution behind the rotor has been obtained as a result of a series of 17 thermo-anemometrical measurements carried out along the width of the rotor, on the probing plane $\Pi_{1}$ of figure $5 \mathrm{a}$. Interpolated results were presented on the following diagrams. Figure 7 presents the distribution of the absolute velocity behind the rotor operating in free space. Analyzing the distributions of velocity obtained for the rotor 


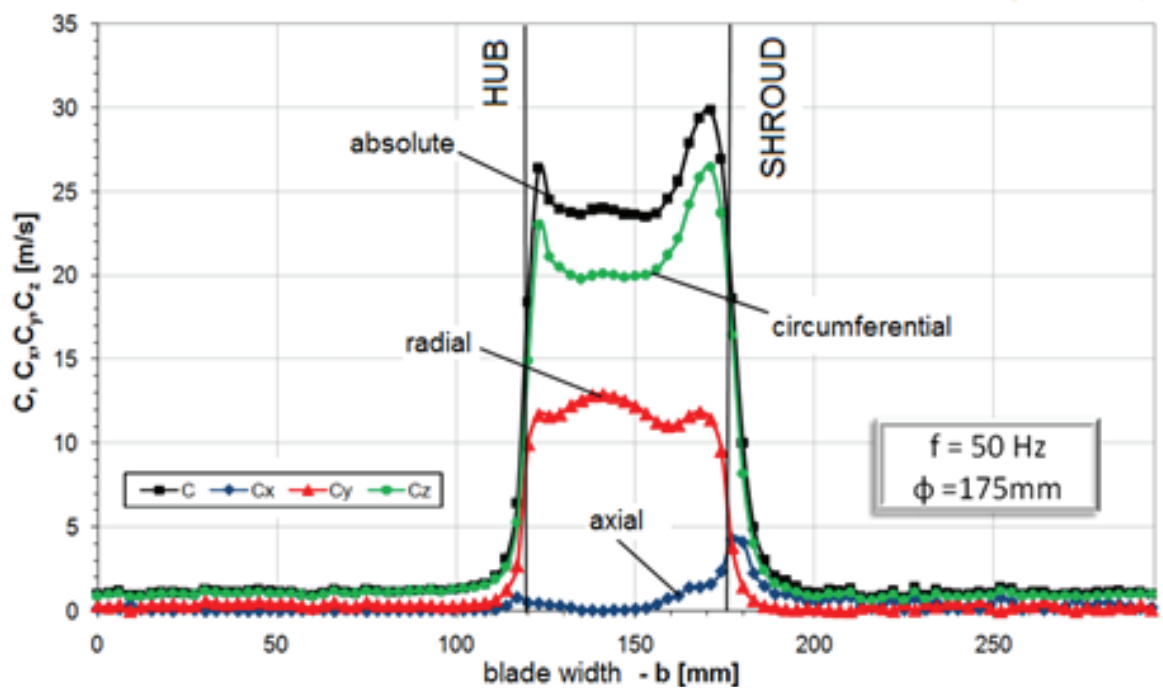

Fig. 6. Velocity distribution behind the rotor obtained in the 1st measuring-series (case F2)

a)

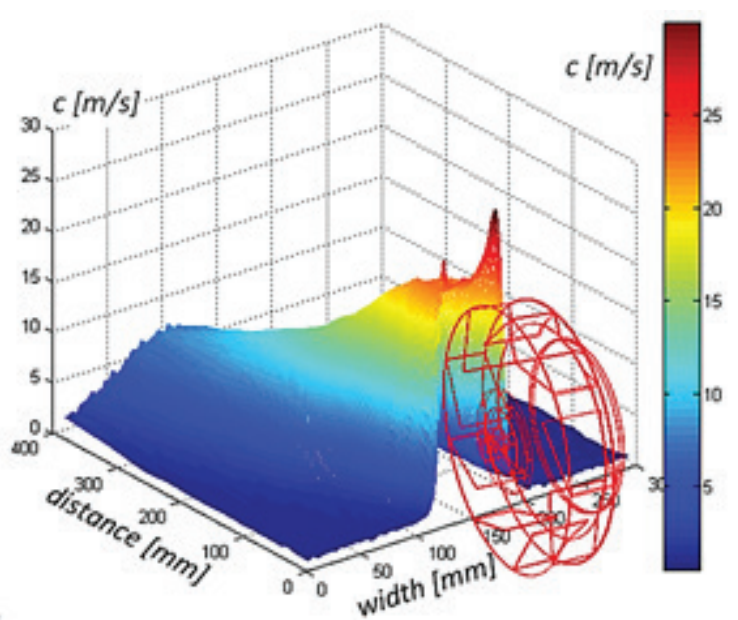

c)

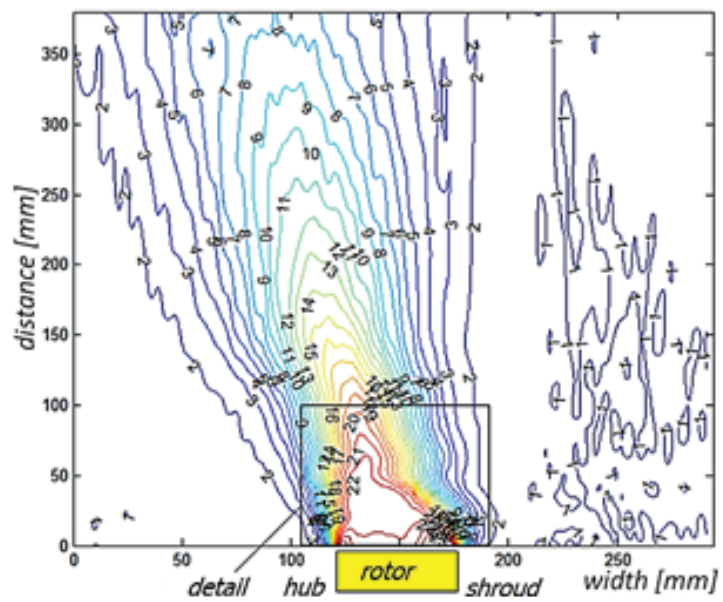

b)

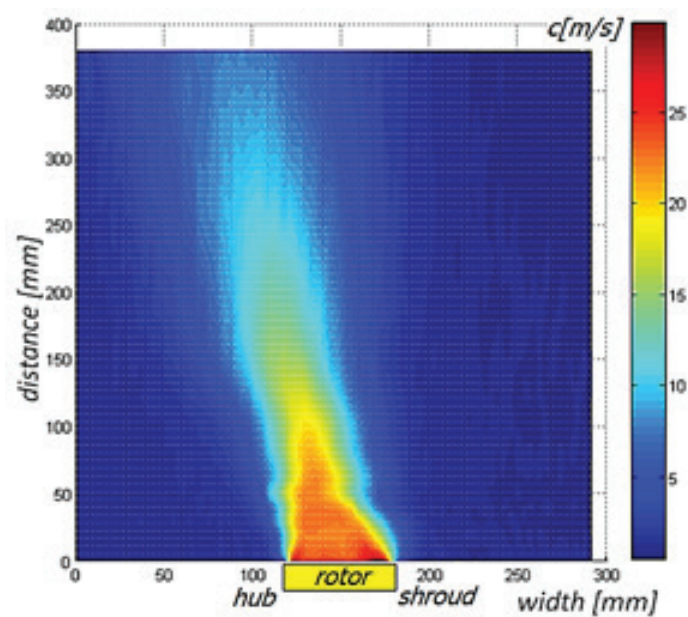

d)

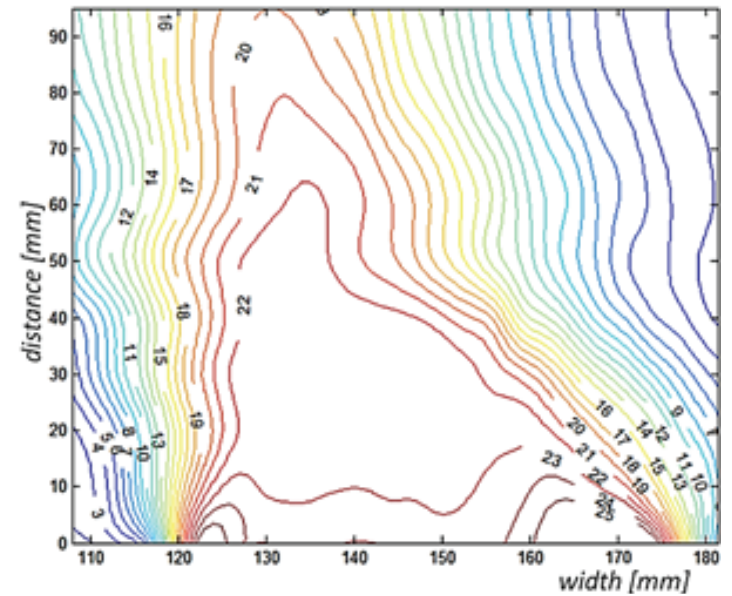

Fig. 7. The distribution of the resultant velocity c behind the rotor F2 working in free space, a) space diagram, b) velocity field, c) isotachs maps, d) detail from the figure $7 \mathrm{c}$

working in free space, it is visible that the air stream flowing out from the rotor into free space has a tendency to deflect to the rear disk surface.

As a result of the presence at the front disk of a large component value of the axial velocity, (fig. 8c), the stream is 'twisted' rearwards. The source of this component is the shape of the forepart of the rotor, where a gentle passage from the axial direction to the pass-piece takes place, and then violently to the radial direction. In the region of the passage to the radial direction there appears an area of the 
detachment of the stream, so that the flow is not parallel to the front disk. From figure $8 \mathrm{~b}$ it is visible that the peripheral speed (tangential velocity) $c_{\mathrm{u}}$ has the highest values at the rotor disk, which may result from the fact that the air stream flowing out in the central part of the blade passage has a large radial component $c_{\mathrm{r}}$ (fig. 8a). This causes the deviation of the circumferential component of velocity towards the radial direction in this part of the section. At the disks this phenomenon is limited.

From the point of view of formulating the optimum geometry of the rotor it is interesting to recognize the spatial structure of the flow in the blade passage. By virtue of restrictions of the methods of classical thermo-anemometry, it was possible to generate the distribution of the absolute velocity and its components only in the exit passage profile (the plane $\Pi_{4}$, fig. $5 \mathrm{~d}$ ). The experiment required additionally the necessity of defining the procedures of measuring point identification time dependence of the distribution of velocities in relation to the rotor blades (Fortuna et al. 2010). Making use of the already mentioned, two-dimensional interpolation by means of the 'cubic' method, we obtained the 3 -D images of the radial velocity components in the blade passage of the operating fan rotor (fig. 8d). It can be noticed that the flow is non-uniform at the blade passage exit. Additional important information, which can be read from figure $8 \mathrm{~d}$, is that a large 'jet' stream passes close to the suction side of the rotor blade. The domination of the flow in the vicinity of the low pressure side differs from the radial compressor, where the jet-flow structure is considered near the pressure side of the rotor blade. a)

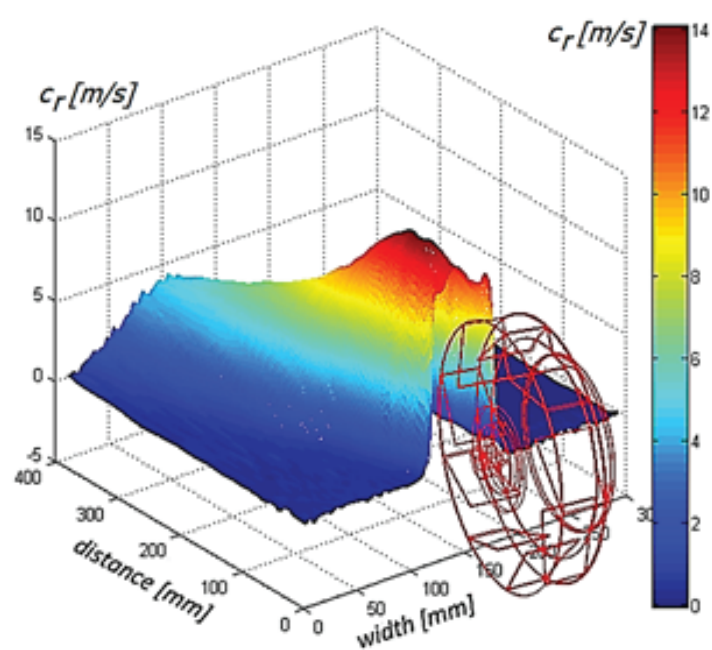

c)

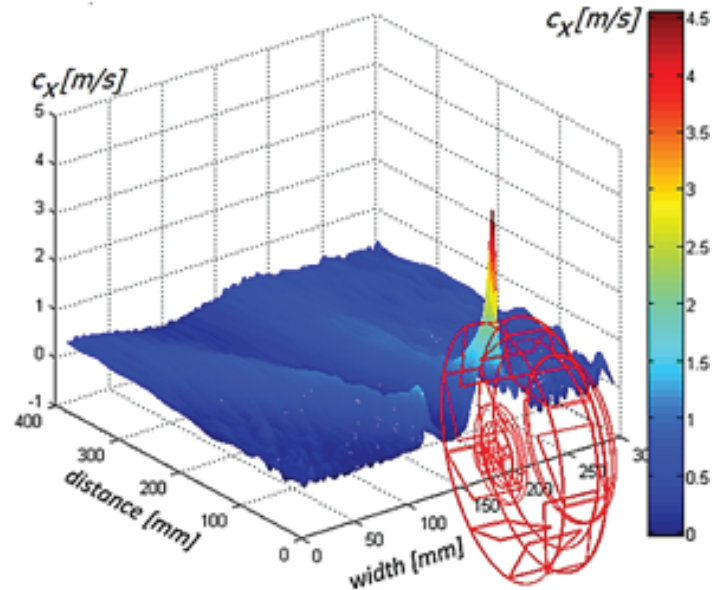

b)

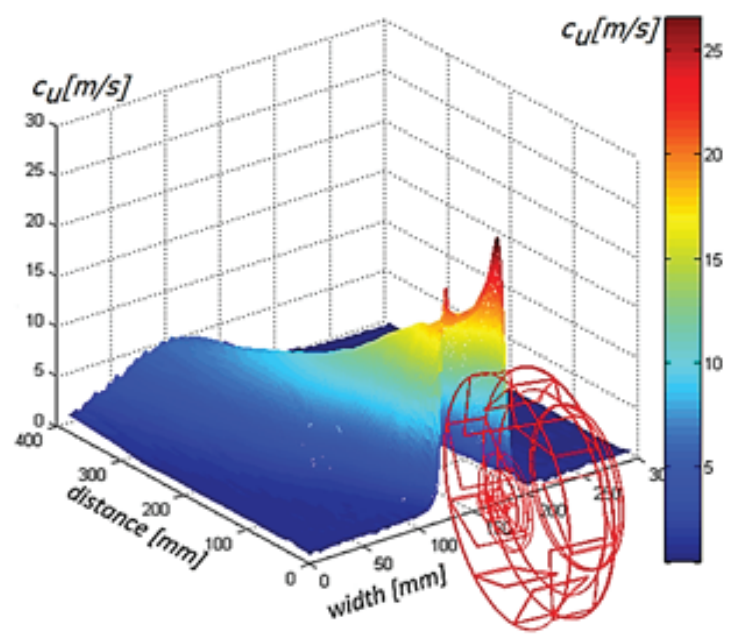

d)

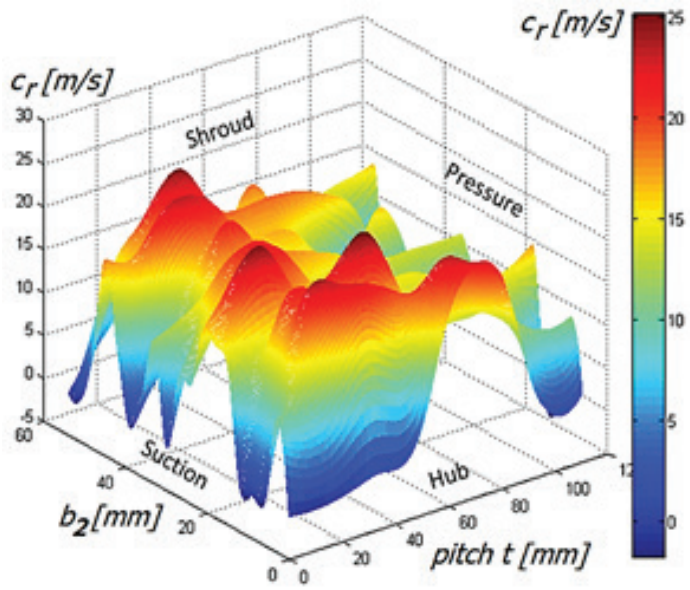

Fig. 8. The structure of the flow behind rotor F2: a) radial velocity component $c_{\mathrm{r} 2}$, b) circumferential $c_{\mathrm{u} 2}, \mathrm{c}$ ) axial $c_{\mathrm{x} 2}$, d) radial $c_{\mathrm{r} 2}$ in the plane $\Pi_{4}-$ the outlet from the blade passage

\subsection{Velocity distribution \\ behind the rotor operating in the volute}

The image of the flow structure behind the rotor covered by a spiral housing, generated as a result of penetration in the plane $\Pi_{2 \mathrm{a}}$, is presented in figure $5 \mathrm{~b}$. Measurement data were collected by displacing the sensor probe along the rotor width from the back wall of the housing towards the front wall. Eleven velocity profiles were collected, each series included 50 measuring points, similar to the example from figure 6 . As a consequence of the interpolation of the results from 550 measuring points, we received the distributions of absolute velocity and its components, shown in figure 9 . 
a)

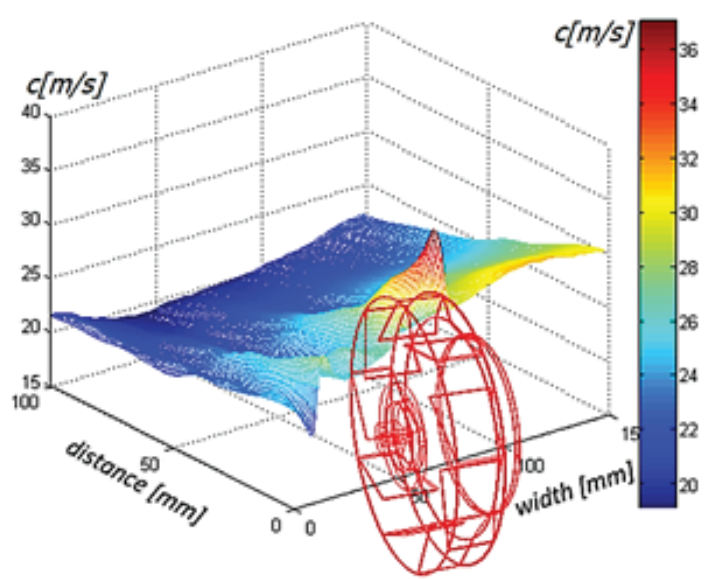

c)

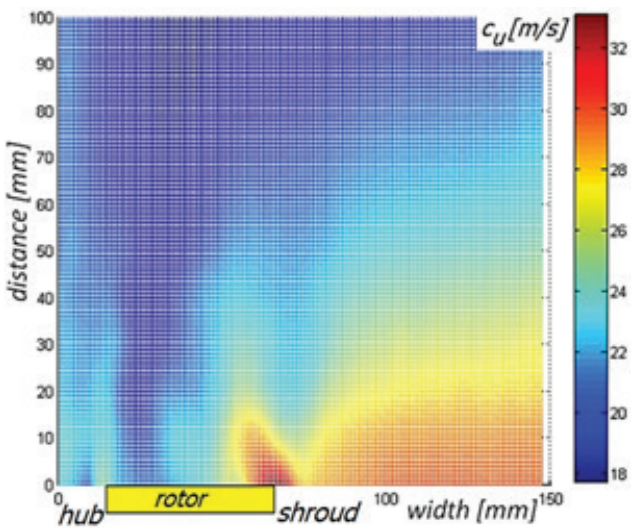

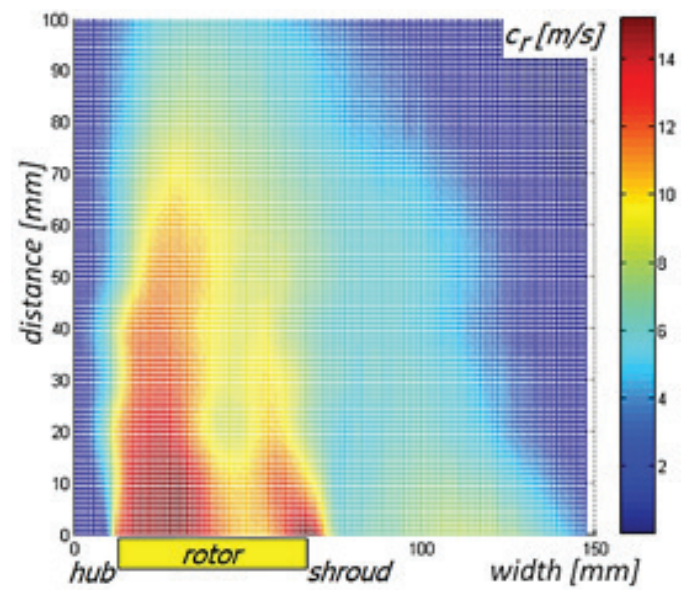

d)

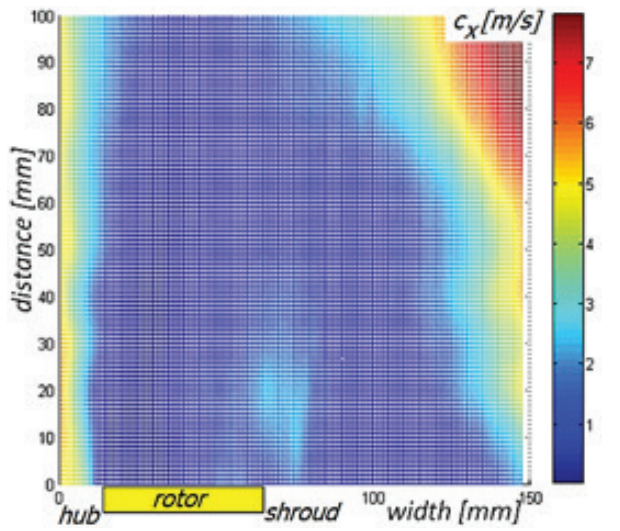

Fig. 9. The structure of the flow behind the rotor inside housing (F2+ob): a) absolute velocity $c, \mathrm{~b})$ radial $\left.c_{\mathrm{r} 2}, \mathrm{c}\right)$ circumferential $c_{\mathrm{u} 2}$, d) axial $c_{\mathrm{x} 2}$ component

Analysing the flow kinematics inside the housing, one can notice that the distribution of the resultant velocity is nearly uniform and it is close to about $24 \mathrm{~m} / \mathrm{s}$. What is not visible here is that the characteristic for these operating conditions has a high absolute velocity peak behind the exit section. The radial velocity distribution is also less important in the formation of the flow. If, for the purpose of comparison, we accept its value to be equal to $15 \mathrm{~m} / \mathrm{s}$, it turns out that the area of disturbance propagation in the case of a free space rotor is about $200 \mathrm{~mm}$, whilst inside the housing it is only $60 \mathrm{~mm}$. It is possible to assume that the exit stream 'is bent' in compliance with the direction of the impeller rotation. Both with and without the housing, the stream of the flowing air is not uniform in the entire exit section.

A greater outflow I occurs in the part close to the rear disk. In the housing, we also do not observe the bend of the rearwards air stream flow. This is due to the influence of the rear housing disk, placed only $15 \mathrm{~mm}$ behind the rotor. A big whirl forms around the intake funnel, in which circumferential velocity dominates, which is visible in figure 9c. Increased values of the axial component on the wall of the rear housing result from the occurrence of the distorted flow in these regions. Moreover, boundary layer flow effects can cause the formation of small whirls. The whirls on the wall of the front housing are a result of leaks caused by the presence of the thermo-anemometrical probe.

\subsection{Velocity distribution inside the inlet chamber}

The picture of the structure inside the inlet chamber was obtained similar as in previous experiments, by sounding the plane $\Pi_{3}$ (fig. 5c). The distribution of the absolute velocity and its components in the inlet chamber of the rotating impeller is presented in figure 10 .

On the basis of the thermo-anemometrical measurements carried out inside the inlet chamber of the fan, we can formulate two fundamental conclusions. Firstly, the flow inside the rotor is completely axially symmetrical (these investigations concern the rotor in free space). Secondly, the air flow structure is heterogeneous in the entire volume of the inlet chamber of the rotor; there are 'dead zones' where air practically doesn't flows (see fig. 11). From the distribution of the turbulence intensity it is clear that in regions of the rear disk of the rotor, between the hub and the blade rim, strongly disturbed flow zones exist (Fortuna and Siwek 2009). In turn, from the radial velocity measurement, presented in figure $10 \mathrm{~b}$, it appears that in this area the fluid flow practically does not shift along the diameter of the rotor.

From figure $10 \mathrm{~d}$ it results that the air stream flowing into the inlet chamber of the rotor has a dominating large axial velocity. The maximum values of this component appear in the flow through the intake funnel. In the intake funnel, and at the walls of the chamber in the transition of the passage 
a)

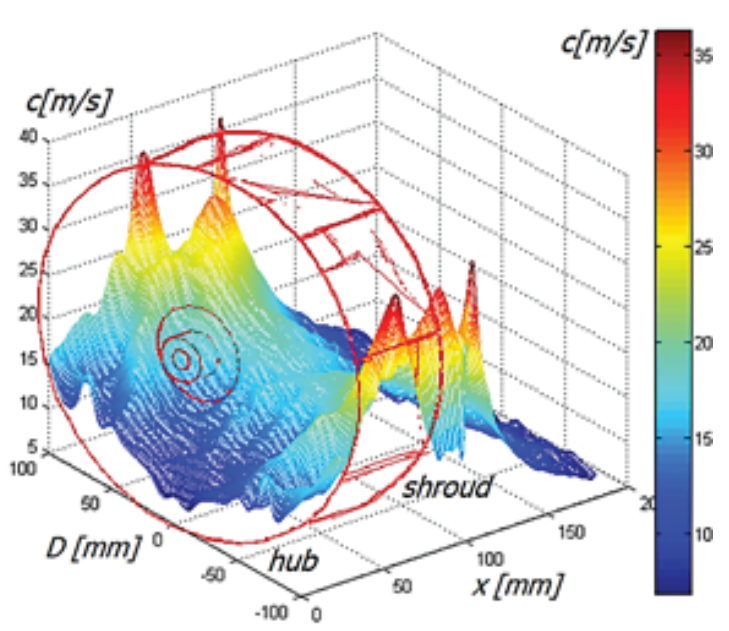

c)

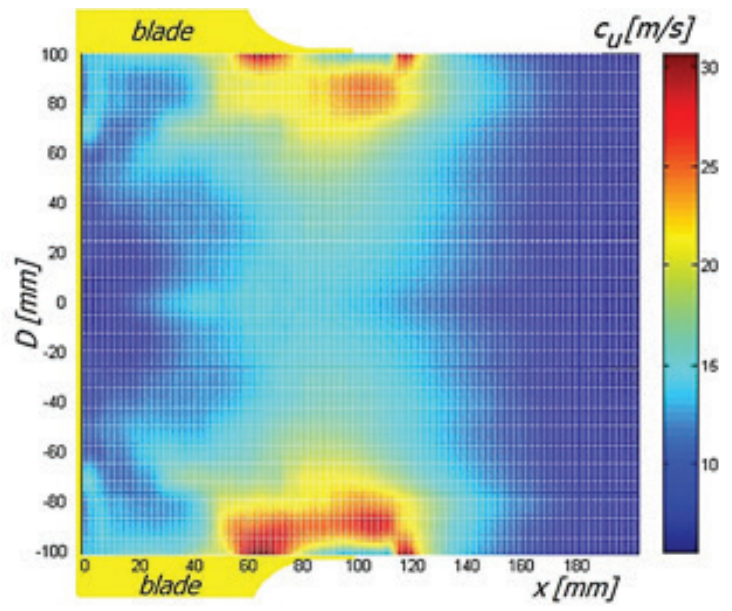

b)

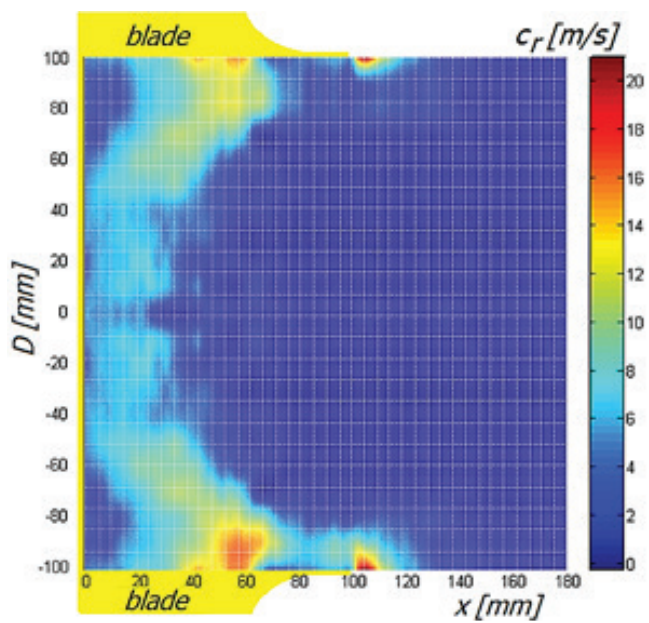

d)

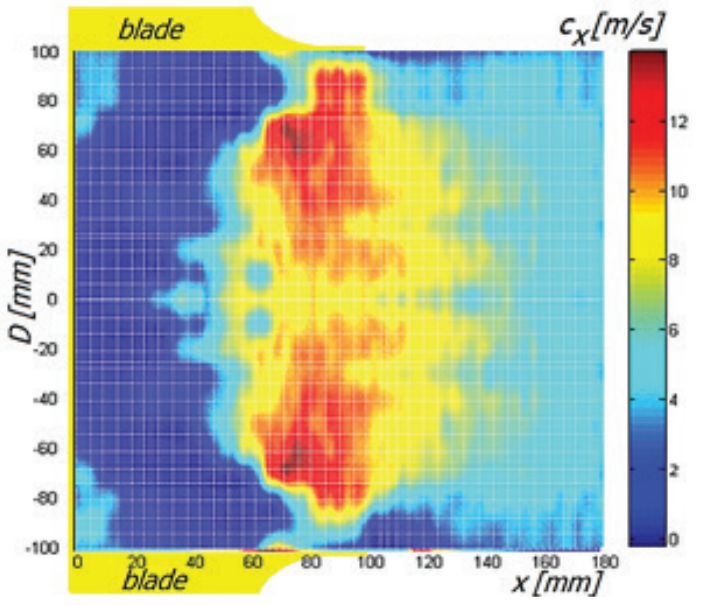

Fig. 10. The structure of the flow inside the inlet chamber: a) absolute velocity $c$, b) radial $c_{\mathrm{r} 2}$, c) circumferential $c_{\mathrm{u} 2}$, d) axial $c_{\mathrm{x} 2}$ component

from the cylindrical part to the pass-piece, there is a circumferential velocity component, which grows with the radius $r_{1}$. The radial velocity, both in the exit profile and in the intake to the rim, is heterogeneous and changes along the blade width $b$. The influx at the intake on the blade rim of the rotor is accumulated at the part close to the front disk.

\section{INFLUENCE OF THE FLOW KINEMATICS ON THE FAN EFFICIENCY}

For the evaluation of the influence of the absolute velocity components on the performance of the machine we averaged its value along the rotor width. This way, with suitable profiles of all velocity components were generated. The aggregated results from laboratory experiments are presented in figure 12 .

Individual profiles are consistent with the configurations of rotor operation of figure. $5 \mathrm{a}$ and $5 \mathrm{~b}$. Measurement series were conducted at a distance of $5 \mathrm{~mm}$ from the trailing edge of the rotor blade.

For the purpose of the facilitation of result interpretation, in Table 1 are collected the average values of absolute velocity, its components and turbulence intensity behind the rotor. Only the values in the rotor outlet, that is along the trailing edge of the exit blade passage, were averaged.

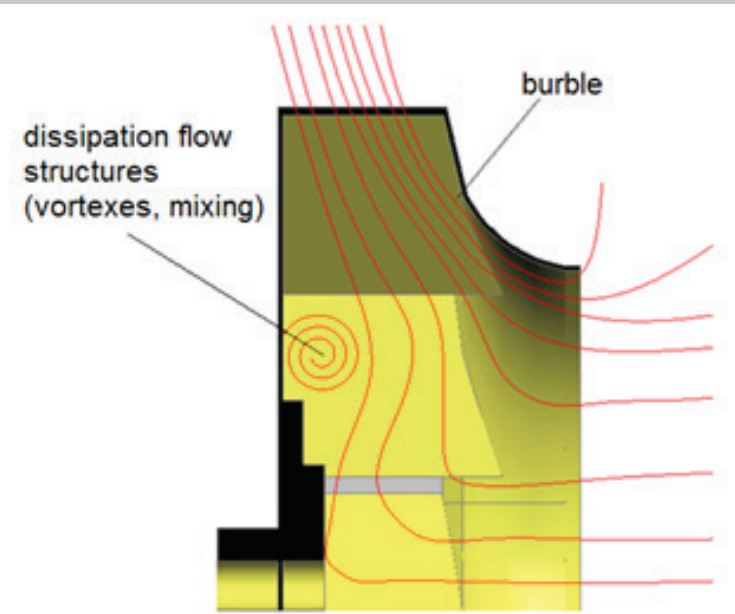

Fig. 11. The flow through the fan rotor - a simplified interpretation of the flow disturbances in the meridional plane

Analysing the distribution of the absolute velocity behind the rotor (fig. 12), it is visible that this velocity for the rotor covered in the housing is about $10-12 \%$ greater than the absolute velocity of the fluid flowing out into free space. This doesn't mean however, that the rotor working in a spiral housing exhibits higher efficiencies. 
a)

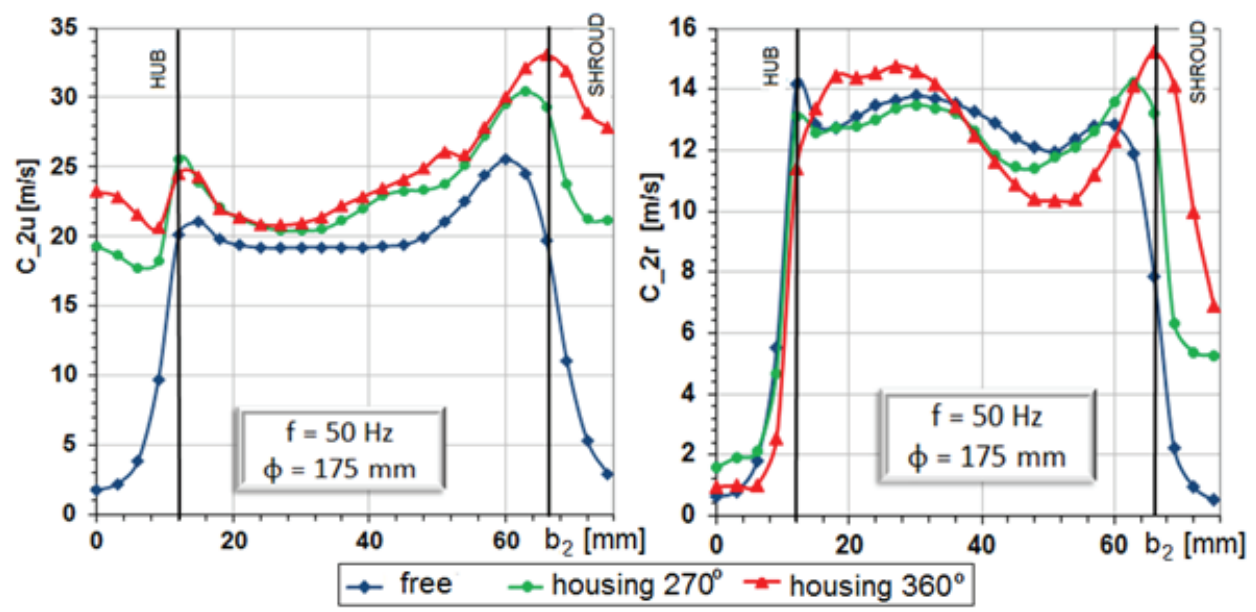

b)

Fig. 12. Profiles of the velocity behind the rotor: a) circumferential, b) radial component

When one compares, in the profile presented in figure $12 \mathrm{~b}$ and position 2 in table 1, the radial component responsible for the efficiency of the fan it is visible that the working configuration does not have much influence on its average value, but only on its distribution along the trailing edge.

The axial velocity is small, so the peripheral velocity is responsible for the difference in performance of the machine (fig. 8 and row 3 in tab. 1).
The housing positively influences the circumferential component, significantly increasing its value. In compliance with Euler's equation (11), this causes the growth of the energy transferred to the fluid, and consequently, the efficiency of the machine. Interpreting the distribution of the turbulence intensity presented in figure 13 , we can assume that although its value for all three measuring situations is equal in the plane of the outlet from the rotor and amounts to about 0.31 , for the outside disks this problem becomes significantly more complicated.

Table 1

Averaged values of the speed along the blade span of the rotor $b_{2}$

\begin{tabular}{|c|l|c|c|c|c|c|}
\hline \multirow{2}{*}{ No. } & \multicolumn{2}{|c|}{ Flow parameter } & \multirow{2}{*}{ Symbol } & \multirow{2}{*}{ Units } & \multicolumn{3}{|c|}{ Measurement conditions } \\
\cline { 5 - 7 } & & & & no housing (F2) & housing $270^{\circ}$ & housing $360^{\circ}$ \\
\hline 1. & Absolute velocity & $c$ & {$[\mathrm{~m} / \mathrm{s}]$} & 24.7 & 27.5 & 28.4 \\
\hline 2. & Radial component & $c_{2 \mathrm{r}}$ & {$[\mathrm{m} / \mathrm{s}]$} & 12.7 & 12.8 & 12.8 \\
\hline 3. & Circumf. component & $c_{2 \mathrm{u}}$ & {$[\mathrm{m} / \mathrm{s}]$} & 20.6 & 23.8 & 24.7 \\
\hline 4. & Axial component & $c_{2 \mathrm{x}}$ & {$[\mathrm{m} / \mathrm{s}]$} & 0.47 & 0.52 & 0.62 \\
\hline 5. & Turbulence intensity & $T$ & {$[-]$} & 0.31 & 0.31 & 0.33 \\
\hline
\end{tabular}

a)

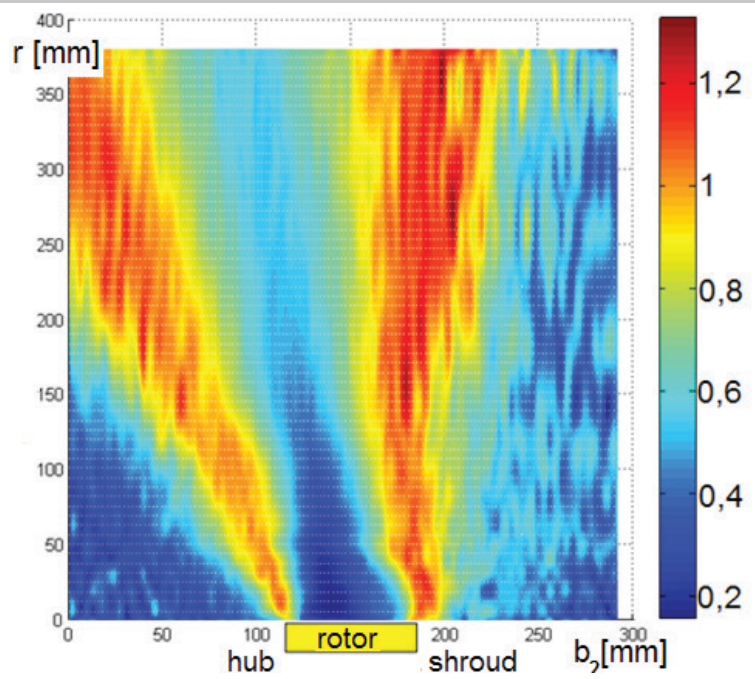

b)

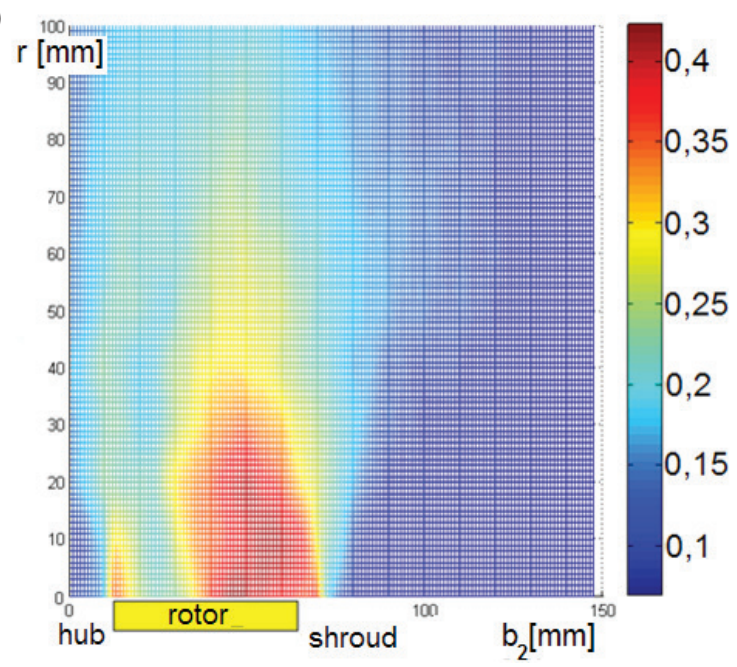

Fig. 13. Distribution of turbulence intensity $T$ behind the operating fan impeller: a) in free space (F2), b) in the housing (F2+ob) 


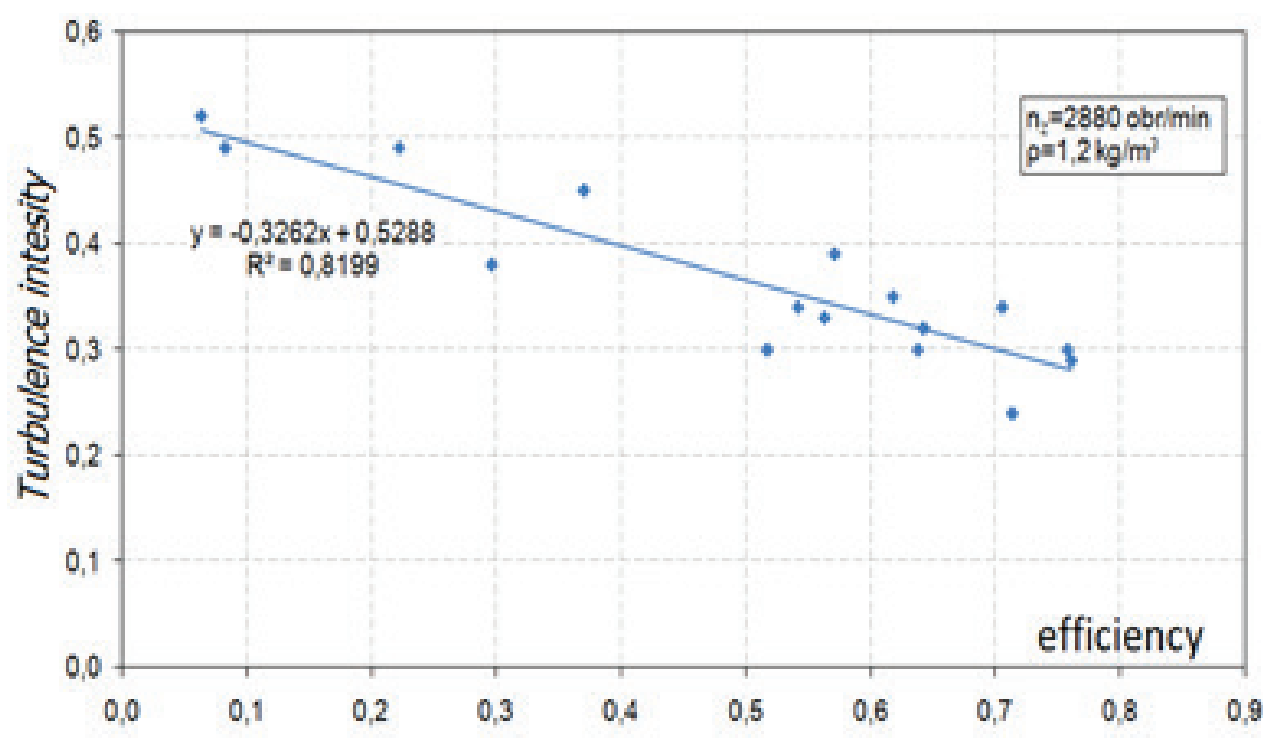

Fig. 14. Approximate correlation between fan efficiency and turbulence intensity

In the case of the absence of the rotor housing, turbulence grows violently, which leads to the dissipation of energy and the deterioration of the energy efficiency of the machine. In figure 13 we show the distribution of the turbulence intensity in the space outside the rotor, which is also the result of the present thermo-anemometrical research. It is visible from figure 13a how the stream of air flowing out of the rotor interacts with the surrounding air. The case of the rotor closed inside the housings is completely different: turbulence intensity is one order of magnitude smaller, and the area of its occurrence is insignificant. The housing significantly and beneficially influences the energy conversion in the low-pressure radial machine, through the improvement of the circumferential component at the rotor outlet and the restriction of the turbulence of the flow outside the rotor.

A summary of the results of the analysis is presented in figure 14 , in the form of a diagram combining the relation between the turbulence intensity of the flow and the radial fan efficiency. It is easy to notice that the correlation between the efficiency of the machine and the turbulence intensity of the flowing air can be regarded as a linear function. One ought to mark that the level of the turbulence intensity was determined according to the relation:

$$
T=\frac{\sqrt{\frac{1}{N-1} \sum\left(c_{\mathrm{i}}-\bar{c}\right)^{2}}}{\bar{c}}
$$

\section{CONCLUSIONS}

Radial fans are one of the flow machines most frequently met, therefore it is important to conduct research aimed at the settlement of relationships that relate the geometric shape with the performance of the machine. The improvement of the efficiency of these machines will not only bring measurable economic results, but also, seemingly invisible, environmental effects, including noise reduction. Less energy consumption and an improvement of the efficiency and better characteristics of fans are the measurable effects expected by the industry.

In this article, findings have been presented on the flow structure through radial fans conducted at the AGH University of Science and Technology in Krakow. The group of authors works currently on the development of new constructions of radial fan rotors, seeking generalized relationships of the geometry with the proper machine performance. The collected material also constitutes the information base for testing the solutions and numerical models of the flow through the rotor, and particularly the validation of CFD techniques. The development of a reliable model will allow us to limit both the costs and time of experiments.

\section{References}

Brzózka J., Dorobczyński L. 2005, Matlab: Software for Scientific and Technical Computing (Matlab, środowisko obliczeń naukowo-technicznych). Mikom Publishing, Warsaw.

Dixon S.L., Hall C.A. 2010, Fluid Mechanics and Thermodynamics of Turbomachinery. 6th ed., Oxford.

Gawor M., Ligęza P., Rachalski A. 1994, Hot-wire anemometric systems for measuring gas velocity components (Termoanemometryczne systemy wyznaczania wektora przeplywu prędkości gazu). III Scientific Conference 'Opto-electronic and Electronic Sensors' COE '94, Zegrze, Poland.

Fortuna S. 2011, The Investigation of the Useful Work and Losses in Radial Fans. Monographs, AGH University of Science and Technology Press, Krakow.

Fortuna S., Siwek T. 2009, Flow Imaging Through the Radial Cascade Flat Profiles on the Basis of Thermoanemometric Experiments. Problems of Mechanical Engineering and Robotics, AGH University of Science and Technology Press, No. 38 (1), pp. 49-62.

Fortuna S., Siwek T., Figiel P. 2010, Visualization of fan outflow in the blade passage on the basis of thermoanemometrics measurements. Mechanics and Control, vol. 29, No.1, pp.11-15.

Ligęza P. 2001, Hot-Wire Anemometric Systems: Structure, Modelling, Instruments and Measuring Systems (Uklady termoanemometryczne - struktura, modelowanie, przyrzady i systemy pomiarowe). AGH University of Science and Technology Press, Krakow.

Witkowski A., Majkut M. 2006, Experimental investigation of inlet guide vane-rotor interaction in a low-speed axial flow compressor stage. Archive of Mechanical Engineering, vol. LIII, No. 1, pp. 23-48. 